\title{
Mededinging
}

\section{Exceptie van de mededingingsbepalingen voor (schijn)zelfstandigen: de zaak FNV Kiem}

\author{
Prof. mr. F.J.L. Pennings*
}

Volgens het Albany-arrest zijn cao-bepalingen die op werknemers betrekking hebben onder bepaalde voorwaarden uitgesloten van de werking van de mededingingsbepalingen van het VWEU (art. 101). In het arrest FNV Kiem is de vraag aan de orde of een bepaling die in een cao is opgenomen reeds om die reden buiten de mededingingsbepalingen valt. Als het antwoord hierop ontkennend is dan is de vraag of de omstandigheid dat de bepaling betrekking heeft op zelfstandigen, maar (ook) bedoeld is ter verbetering van arbeidsvoorwaarden of werkgelegenheid van werknemers tot gevolg heeft dat de mededingingsbepalingen dergelijke cao-bepalingen niet verbieden. Het Hof van Justitie antwoordde dat bepalingen die betrekking hebben op zelfstandigen niet buiten de werkingssfeer van artikel 101 VWEU vallen. Dit is echter anders wanneer het om schijnzelfstandigen gaat. Vervolgens gaf het Hof van Justitie een ruime definitie van 'schijnzelfstandigen', zodat het arrest meer mogelijkheden geeft om cao-bepalingen die betrekking hebben op 'zelfstandigen' te maken dan op het eerste gezicht lijkt.

Hvf 4 december 2014, zaak C-413/13, FNV Kiem, ECLI:EU:C:2014:2411

\section{Inleiding}

Op 4 december 2014 heeft het Hof van Justitie het arrest FNV Kunsten Informatie en Media tegen Staat der Nederlanden gewezen (hierna: FNV Kiem-arrest), dat betrekking heeft op de vraag of in cao's minimumtarieven afgesproken mogen worden ten behoeve van personen die werken op overeenkomst van opdracht. Dit is een interessante vraag, aangezien problemen met mededingingsrecht zich al onmiddellijk lijken voor te doen. caobepalingen zijn echter wel voor werknemers toegestaan,

Prof. mr. F.J.L. (Frans) Pennings is Hoogleraar sociaal recht aan de Universiteit Utrecht en tevens gasthoogleraar aan de Universiteit van Gotenburg. waardoor mededinging op lonen (en daarmee ook kosten voor werkgevers) beperkt kan worden. Waarom zou dat dan niet mogen voor zelfstandigen in bepaalde sectoren, zeker als ze in hoge mate afhankelijk zijn van één opdrachtgever en ze op lage tarieven zijn aangewezen? De verhouding van cao-bepalingen tot het mededingingsrecht kwam eerder aan de orde in het arrest Alba$n y ;^{1} \mathrm{ik}$ zal dat hierna behandelen. Vervolgens zal ik het $F N V$ Kiem-arrest en de voorgeschiedenis ervan bespreken. Ten slotte ga ik in op de betekenis van dit arrest.

\section{De Albany-jurisprudentie}

Eind jaren negentig werd aan het Hof van Justitie de vraag voorgelegd of verplichte aansluiting bij een pensioenfonds in overeenstemming is met de Europese mededingingsbepalingen. In concreto ging het om weigering van het verzoek van de betreffende werkgevers om vrijgesteld te worden van de verplichte aansluiting bij het bedrijfspensioenfonds. Ze wilden liever een eigen pensioenregeling bij hun verzekeringsmaatschappij aanhouden. De vraag leidde tot het arrest Albany. ${ }^{2}$

Het Hof van Justitie antwoordde dat (wat nu is) artikel 3 VEU een beleid op sociaal gebied verlangt: de Gemeenschap heeft onder meer tot taak het bevorderen van een harmonische en evenwichtige ontwikkeling van econo-

1. HvJ 21 september 1999, zaak C-67/96, Albany, Jur. 1999, p. I-5751, ECLI:EU:C:1999:430. Op dezelfde dag werd ook arrest gewezen in vergelijkbare zaken: HvJ 21 september 1999, zaak C-219/97, Drijvende Bokken, ECLI:EU:C:1999:437; en HvJ 21 september 1999, gevoegde zaken C-115/97 en C-117/97, Brentjes, ECLI:EU:C:1999:434. Zie voor een studie over de gevolgen van deze jurisprudentie R. Bruun en J. Hellsten (red.), Collective Agreement and Competition in the EU, Kopenhagen 2001; en M.S. Wirtz, Collisie tussen cao's en mededingingsrecht, Deventer: Kluwer 2006.

2. Zie ook E.M.H. Loozen, 'CAO's, bedrijfspensioenfondsen en het EGmededingingsrecht', NTER 1999/11, p. 274-285; K.J.M. Mortelmans en H.A.G. Temmink, 'Verplichte deelneming in bedrijfspensioenfondsen en het vrije verkeer van diensten en de vrije vestiging. De Hoge Raad verwijst niet. Terecht?', NTER 1999/6, p. 139-145; J.J.M. Sluys, 'Toepasselijkheid van het mededingingsrecht op sociaalrechtelijke vraagstukken', NTER 1999, p. 37-39. 
mische activiteiten en een hoog niveau van werkgelegenheid, en van sociale bescherming. De (huidige) artikelen 153-161 VWEU bepalen voorts dat de Europese Commissie tot taak heeft tussen de lidstaten een nauwe samenwerking op sociaal gebied te bevorderen, met name op het terrein van het recht zich te organiseren in vakverenigingen en van collectieve onderhandelingen tussen werkgevers en werknemers. ${ }^{3}$ Het Hof van Justitie overwoog dat hoewel een zekere mededingingsbeperkende werking eigen is aan collectieve overeenkomsten tussen werkgevers- en werknemersorganisaties, de verwezenlijking van de met dergelijke overeenkomsten nagestreefde doelstellingen van sociale politiek ernstig zou worden belemmerd indien de sociale partners bij hun gezamenlijke inspanning de werkgelegenheids- en arbeidsvoorwaarden te verbeteren zich aan (het huidige) artikel 101 lid 1 VWEU moesten houden. ${ }^{4}$ Uit een nuttige en coherente uitlegging van de bepalingen van het Verdrag, gelezen in hun onderling verband, volgt derhalve dat overeenkomsten die met dergelijke doelstellingen in het kader van collectieve onderhandelingen tussen sociale partners worden gesloten wegens hun ard en hun doel moeten worden geacht niet onder artikel 101 lid 1 van het Verdrag te vallen, aldus het Hof van Justitie. $^{5}$

Derhalve moest worden onderzocht of (1) de bepaling tot stand is gekomen door collectieve onderhandelingen van werkgevers of werkgeversorganisaties enerzijds en werknemersorganisaties anderzijds en (2) het doel van de in geding zijnde overeenkomst rechtvaardigt dat deze buiten de werkingssfeer van artikel 101 lid 1 van het Verdrag valt. ${ }^{6}$

\section{Immuniteit van cao's en zelfstandigen}

Geldt de immuniteit van het mededingingsrecht alleen voor cao's die betrekking hebben op werknemers? En geldt deze alleen voor primaire arbeidsvoorwaarden zoals lonen en pensioenen? Deze onderwerpen waren aan de orde in de FNV Kiem-zaak. Aangezien zzp'ers (zelfstandigen zonder personeel) soms in een vergelijkbare afhankelijke positie als werknemers verkeren, sommigen van hen (erg) lage inkomens hebben, maar niet de voor werknemers geldende bescherming hebben, en aangezien ze door hun lagere kosten de werkgelegenheid van werknemers kunnen bedreigen nam de FNV Kiem (hierna: FNV) het initiatief om een cao-regeling te treffen voor concertremplaçanten. Concertremplaçanten fungeren in een orkest als vervangers van vaste orkestleden; sommigen van hen hebben een overeenkomst van opdracht en worden daarom door de orkesten behandeld als zelfstandigen. Anderen hebben een arbeidsovereenkomst.

De Cao voor Remplaçanten Nederlandse Orkesten werd gesloten tussen FNV Kiem en de Nederlandse toonkunstenaarsbond enerzijds (die zowel werknemers als zelfstandigen vertegenwoordigen) en de werkgeversvereniging Vereniging van Stichtingen Remplaçanten Nederlandse Orkesten anderzijds. De cao voorzag onder andere in minimumtarieven voor remplaçanten die werken op basis van een overeenkomst van opdracht. De FNV kondigde bij het afsluiten van de cao aan dat ze dergelijke bepalingen ook in cao's voor andere beroepsgroepen wilde opnemen.

De Nederlandse Wet op de collectieve arbeidsovereenkomst staat overigens toe dat een cao betrekking heeft op overeenkomsten van opdracht of aanneming van werk. ${ }^{7}$ Minimumtarieven in een cao voor degenen die een overeenkomst van opdracht hebben, dragen er enerzijds toe bij dat deze personen een betere inkomenspositie verkrijgen; anderzijds is een bodem onder hun tarieven ook in het belang van werknemers die anders uit de markt geprijsd kunnen worden.

Over de vraag of dit wenselijk is, wordt heel verschillend gedacht. Een van de zzp-organisaties noemde het een 'volstrekt ridicule' gedachte om in cao's dergelijke bepalingen op te nemen, aangezien ondernemers nu juist zelf hun risico's willen dragen. ${ }^{8}$ Hier valt tegenin te brengen dat er sprake kan zijn van concurrentie op arbeidskosten: zzp'ers kunnen werknemers die hetzelfde werk doen uit de markt prijzen. Daarnaast hebben sommige zzp'ers zo'n zwakke onderhandelingspositie dat ze heel marginale inkomens hebben; ook om die reden kan een bodem in de tarieven gewenst zijn.

\section{De Nederlandse}

$$
\begin{aligned}
& \text { Mededingingsautoriteit (NMa) } \\
& \text { en bepalingen voor zzp'ers in } \\
& \text { cao's }
\end{aligned}
$$

De Cao voor Remplaçanten met bepalingen voor personen die op basis van een overeenkomst voor opdracht werken en de aankondiging van de FNV dat ze meer van dergelijke cao's wilde afsluiten waren aanleiding voor de $\mathrm{NMa}$ (Nederlandse Mededingingsautoriteit, later opgegaan in Autoriteit Consument \& Markt) om in gesprek te gaan met de cao-partijen. Hierin maakte de NMa duidelijk dat zij de bepalingen die betrekking hadden op zelfstandigen in strijd achtte met het mededingingsrecht. In het Visiedocument Cao-tariefbepalingen voor 
zelfstandigen en de Mededingingswet $(2007)^{9}$ onderbouwde de NMa haar standpunt. Naar aanleiding van dit standpunt hebben de werkgeversorganisaties de cao opgezegd.

De NMa benaderde de vraag of de gewraakte bepalingen in strijd met het mededingingsrecht zijn door na te gaan of er sprake is van ondernemingen (aan wie immers art. $101 \mathrm{VWEU}$ het kartelverbod oplegt). Ten aanzien van werknemers stelde zij vast dat dit geen ondernemingen zijn, angezien zij tijdens de duur van hun arbeidsverhouding geïntegreerd zijn in de onderneming waarvoor zij werken. ${ }^{10} \mathrm{Zij}$ dragen niet het directe commerciele risico van een transactie. De NMa stelde vervolgens dat natuurlijke personen die anders dan als werknemers als zelfstandige deelnemers aan het economisch verkeer tegen beloning goederen of diensten op een bepaalde markt aanbieden ondernemingen zijn in de zin van het mededingingsrecht. Vakorganisaties zijn daarom, voor zover zij optreden voor zelfstandigen, een ondernemingsvereniging.

De NMa verwierp het argument dat minimumtariefbepalingen voor zelfstandigen de neerwaartse druk op de cao voor werknemers verminderen. ${ }^{11} \mathrm{Zij}$ betoogde dat het streven om met de vastlegging van vaste prijzen of minimumprijzen voor zelfstandigen bij te dragen tot een verbetering van de werkgelegenheids- en arbeidsvoorwaarden van werknemers geen louter sociale doelstelling is, aangezien de hieruit voortvloeiende mededingingsbeperkingen verder gaan dan noodzakelijk is voor het nastreven van deze doelstelling. Werknemers zijn eerder gebaat bij afspraken die hun werkgelegenheids- en arbeidsvoorwaarden rechtstreeks verbeteren, aldus de $\mathrm{NMa}$, zoals belonings- of pensioenafspraken.

De NMa geeft hiermee wel erg weinig blijk van begrip voor de situatie van de concertleden en remplaçanten op arbeidsovereenkomst. Ze kan wel stellen dat werknemers vooral gebaat zijn bij een hoger loon, maar als de werknemers daardoor uit de markt gedrukt worden en hun baan verliezen, leveren loononderhandelingen weinig op.

\section{FVN Kiem - Nederland: de procedure bij rechtbank en Hof 's-Gravenhage}

De FNV heeft vervolgens een procedure gestart tegen de NMa bij de rechtbank te 's-Gravenhage om in een verklaring voor recht vast te laten stellen dat de minimumtarieven vastgesteld in een cao niet in strijd zijn met het mededingingsrecht. Het is overigens uniek dat de Staat gedaagd wordt vanwege een visiedocument van de NMa.

De rechtbank wees de eis van de FNV af. ${ }^{12}$ De FNV stelde vervolgens hoger beroep in bij het gerechtshof te 's-Gravenhage, dat prejudiciële vragen stelde aan het Hof van Justitie. De verwijzende rechter merkte hierbij de zelfstandige remplaçanten voorlopig aan als 'ondernemer' op grond van het feit dat hun inkomsten afhankelijk zijn van de opdrachten die zij zelfstandig op de markt van remplaçanten weten te verwerven, zij als zodanig ook concurreren met andere remplaçanten en zij investeren in muziekinstrumenten. Het merkte niettemin op dat de oplossing van de onderhavige zaak niet duidelijk kon worden afgeleid uit het Verdrag noch uit de rechtspraak van het Hof van Justitie. ${ }^{13}$ De vragen van het Hof 's-Gravenhage waren de volgende:

'1. Moeten de mededingingsregels van het Unierecht aldus worden uitgelegd dat een bepaling in een collectieve arbeidsovereenkomst, afgesloten tussen verenigingen van werkgevers en van werknemers waarin is bepaald dat zelfstandigen die op basis van een overeenkomst van opdracht voor een werkgever hetzelfde werk verrichten als de werknemers die onder de werking van de cao vallen, een bepaald minimumtarief moeten ontvangen, reeds op grond dat die bepaling voorkomt in een cao, buiten de werkingssfeer van artikel $101 \mathrm{VWEU}$ valt?

2. Indien het antwoord op de eerste vraag ontkennend luidt, valt die bepaling dan buiten de werkingssfeer van artikel 101 VWEU in het geval deze bepaling (mede) bedoeld is ter verbetering van de arbeidsvoorwaarden van de werknemers die onder de werking van de cao vallen en is het daarbij nog van belang of die arbeidsvoorwaarden daardoor rechtstreeks of slechts indirect worden verbeterd?'

\section{De conclusie van advocaat- generaal Wahl}

De advocaat-generaal is van mening dat cao-bepalingen die betrekking hebben op zelfstandigen niet buiten de mededingingsbepalingen vallen als zij namens en in het belang van zelfstandigen overeen zijn gekomen. Hij gaat vervolgens in op de vraag of tarieven voor zelfstandigen in het belang kunnen zijn van werknemers, namelijk om te voorkomen dat ze weggeconcurreerd worden.

Nederland had aangevoerd dat alleen bepalingen die rechtstreekse beogen bij te dragen aan de verbetering van arbeidsvoorwaarden van werknemers onder de Albany-uitzondering vallen.
9. Nederlandse Mededingingsautoriteit, Cao-tariefbepalingen voor zelfstandigen en de Mededingingswet, Visiedocument van de Nederlandse Mededingingsautoriteit, Den Haag, december 2007 (hierna: Visiedocument NMa 2007)

10. Visiedocument NMa 2007, p. 8.

11. Visiedocument NMa 2007, p. 24
12. Rb. Den Haag 27 oktober 2010, ECLI:NL:RBSGR:2010:BO3551, AB 2012, 188, m.nt. I. Sewandono, USZ 2012/54, m.nt. M.J.A.C. Driesen.

13. <www.ie-forum.nl/backoffice/uploads/file/IE-Forum $\% 20 \mathrm{Hof} \% 20$ Den \%20Haag\%209\%20juli\%202013,\%20zaaknr_\%20200_082_996_ 01;\%20zaak\%20C-413_13\%20(FNV\%20KIEM\%20tegen\%20De \%20Staat).pdf>, arrest FNV Kiem, punt 15. 
De advocaat-generaal overwoog dat de bescherming van de huidige en toekomstige werkgelegenheid voor werknemers kan worden beschouwd als een rechtstreekse verbetering van hun werkgelegenheids- en arbeidsvoorwaarden. Wanneer het vanuit economisch oogpunt voor werkgevers gemakkelijk zou zijn werknemers door zelfstandigen te vervangen, zou dat er licht toe kunnen leiden dat heel wat werknemers onmiddellijk hun baan verliezen of geleidelijk aan worden gemarginaliseerd. Ook zou het de onderhandelingspositie van werknemers aanmerkelijk kunnen verzwakken. Dit zou ertoe kunnen leiden dat men aanneemt dat de voorwaarden in de cao die betrekking hebben op zelfstandigen ten voordele van de arbeidsvoorwaarden van werknemers zijn en dan vallen ze wel buiten de mededingingsbepalingen van het verdrag.

Vervolgens was het, volgens de advocaat-generaal, aan het Hof 's-Gravenhage om op basis van alle hem door partijen in het hoofdgeding overgelegde gegevens en bewijzen vast te stellen of de Albany-uitzondering daadwerkelijk van toepassing is. Het moet waarschijnlijk zijn dat zonder de betrokken bepalingen een aanzienlijk aantal werknemers tegen lagere kosten door zelfstandigen zal worden vervangen, bijvoorbeeld door onmiddellijk ontslag van werknemers of via een geleidelijke besparing door werknemers van wie de arbeidsovereenkomst afloopt niet te vervangen. In de tweede plaats moet de nationale rechter nagaan of de bepalingen verder gaan dan nodig is om de doelstelling van voorkoming van sociale dumping te verwezenlijken. Een voorbeeld van bepalingen die verder gaan dan nodig is, zijn cao-bepalingen die werknemers een grotere bescherming bieden ten opzichte van zelfstandigen dan ten opzichte van andere werknemers. Als dat het geval is dan zouden ze niet buiten de werking van de mededingingsbepalingen vallen.

De advocaat-generaal brengt bestrijding van sociale dumping dus onder de rechtstreekse verbetering van de werkgelegenheid en de arbeidsvoorwaarden. Daarmee geeft hij het element 'rechtstreeks' niet de betekenis dat het de mogelijkheid uitsluit dat bepalingen met betrekking tot zelfstandigen de werkgelegenheid en arbeidsvoorwaarden van werknemers verbeteren. Dat is positief, de onderdelen die in een cao kunnen worden opgenomen zonder problemen op te leveren met het mededingingsrecht moeten niet te beperkt gedefinieerd worden.

Deze benadering geeft een wel heel zware taak aan de Nederlandse rechter. Daarnaast zal de toets in de praktijk weinig soelaas bieden aan de bonden. Als immers aangetoond kan worden dat werknemers ingeruild zijn door zelfstandigen, dan is het al te laat om dat nog te voorkomen door een cao. En of die cao dan nog effect heeft voor de nog zittende werknemers zal vaak weer bestreden worden.

\section{Het FNV Kiem-arrest}

Het Hof van Justitie stelde allereerst vast dat het bevoegd was om deze vragen te beantwoorden, ook al betreft het een zuiver interne kwestie. Artikel 6 lid 1 Mededingingswet geeft immers de wezenlijke inhoud van artikel $101 \mathrm{VWEU}$ weer en volgens het verwijzingsarrest heeft de wetgever uitdrukkelijk beoogd het Nederlandse mededingingsrecht te harmoniseren met het mededingingsrecht van de Unie en moest artikel 6 lid 1 Mededingingswet worden uitgelegd op een wijze die strookt met artikel 101 VWEU. Voorkomen moet worden dat overgenomen bepalingen van Unierecht op uiteenlopende wijzen worden uitgelegd. ${ }^{14}$

Het Hof van Justitie overwoog vervolgens dat de betrokken overeenkomst is gesloten tussen een werkgeversorganisatie en gemengd samengestelde organisaties van werknemers, die overeenkomstig intern recht niet alleen voor werknemersremplaçanten, maar ook voor aangesloten zelfstandige remplaçanten hebben onderhandeld. ${ }^{15}$ Onderzocht moet worden of een dergelijke overeenkomst gezien haar aard en doel tot stand is gekomen in het kader van collectieve onderhandelingen tussen sociale partners en of het op grond daarvan gerechtvaardigd is dat zij voor het deel dat betrekking heeft op de minimumtarieven voor zelfstandige remplaçanten buiten de werkingssfeer van artikel 101 lid 1 VWEU valt.

Het Hof van Justitie stelde vast dat dienstverrichters als bedoelde remplaçanten weliswaar dezelfde werkzaamheid uitoefenen als werknemers, maar in beginsel ondernemingen in de zin van artikel 101 lid 1 VWEU zijn, aangezien zij hun diensten tegen beloning aanbieden op een bepaalde markt en zij hun werkzaamheid ten opzichte van hun opdrachtgever als onafhankelijke marktdeelnemers verrichten. ${ }^{16}$

Het VWEU heeft weliswaar een sociale dialoog voor ogen, maar bevat geen bepalingen die - zoals artikelen $53 \mathrm{VWEU}$ en $155 \mathrm{VWEU}$ - zelfstandigen aanmoedigen een dergelijke dialoog in gang te zetten met opdrachtgevers waarbij zij diensten verrichten op basis van een overeenkomst van opdracht en dus met die werkgevers collectieve overeenkomsten te sluiten ter verbetering van hun werkgelegenheids- en arbeidsvoorwaarden. ${ }^{17}$

In die omstandigheden moet worden geconstateerd, aldus het Hof van Justitie, dat de omstreden cao-bepaling, doordat zij door een werknemersorganisatie is gesloten namens en voor rekening van de bij deze organisatie aangesloten zelfstandigen, niet het resultaat is van collectieve onderhandelingen tussen sociale partners en niet op grond van haar aard buiten de werkingssfeer van artikel 101 lid 1 VWEU kan vallen. ${ }^{18}$ Tot zover volgde het Hof van Justitie de Nma en ook de Nederlandse rechter. Het Hof van Justitie gaat niet expliciet in op de vraag - gesteld door het Hof 's-Gravenhage en 
wel behandeld door de advocaat-generaal - of bepalingen voor zelfstandigen geoorloofd zijn omdat ze ten gunste van de werkgelegenheid en het loonpeil van werknemers kunnen zijn.

Vervolgens krijgt het arrest een interessante draai. Het Hof van Justitie besprak namelijk de mogelijkheid dat bedoelde dienstverleners, namens en voor rekening van wie de werknemersorganisatie onderhandelingen heeft gevoerd, in werkelijkheid schijnzelfstandigen vormen, dat wil zeggen dienstverleners wier situatie vergelijkbaar is met die van werknemers.

\section{Schijnzelfstandigen}

Een schijnzelfstandige is iemand die zich voordoet als zelfstandige of als zodanig wordt behandeld, terwijl hij in werkelijkheid werknemer is. Dat betekent dat van belang is of iemand volgens de in het nationale arbeidsrecht neergelegde criteria een arbeidsovereenkomst heeft. Enigszins vereenvoudigd samengevat en voor zover hier van belang betekent dat naar Nederlands arbeidsrecht dat er een gezagsrelatie moet bestaan tussen werkende en de opdrachtgever en dat betrokkene de arbeid persoonlijk moet verrichten (dus zich niet zonder toestemming van de werkgever mag laten vervangen). ${ }^{19}$ Dat zijn soms, en zeker in twijfelgevallen, vaak lastige criteria om aan te tonen.

Het Hof van Justitie nu overwoog met betrekking tot de vraag of er sprake was van schijnzelfstandigen, dat een dienstverlener zijn hoedanigheid van zelfstandige marktdeelnemer, en dus van ondernemer, kan verliezen, wanneer hij niet zelfstandig zijn marktgedrag bepaalt, maar volledig afhankelijk is van zijn opdrachtgever, doordat hij geen van de uit de werkzaamheid van deze laatste voortvloeiende financiële en commerciële risico's draagt en werkzaam is als in de onderneming van bedoelde opdrachtgever opgenomen medewerker. ${ }^{20}$

Voorts moet, aldus het Hof van Justitie, het begrip werknemer in de zin van het Unierecht worden gedefinieerd aan de hand van objectieve criteria die kenmerkend zijn voor de arbeidsverhouding, rekening houdend met de rechten en verplichtingen van de betrokken personen. ${ }^{21}$ Dit kan dus een andere definitie zijn dan volgens het nationale recht. Met andere woorden, de kwalificatie als zelfstandige naar nationaal recht sluit niet uit dat een persoon moet worden aangemerkt als werknemer in de zin van het Unierecht, indien zijn zelfstandigheid slechts fictief is en dus een echte arbeidsverhouding verhult, aldus het Hof van Justitie. ${ }^{22}$

19. Voor sociale verzekeringen gelden ruimere criteria, aangezien de art. 4 en 5 van het Besluit uitbreiding en beperking kring verzekerden werknemersverzekeringen gelijkstellingsbepalingen kennen voor bepaalde categorieën werkenden die geen arbeidsovereenkomst hebben. Ze zijn dan verzekerd en moeten premies betalen; ze zijn daarmee echter nog geen werknemer, en hebben dus niet de rechten en plichten volgens het arbeidsrecht.

20. FNV Kiem, punt 33

21. FNV Kiem, punt 34

22. FNV Kiem, punt 35
Het Hof van Justitie komt dan tot de volgende conclusie: aan de status van werknemer in de zin van het Unierecht wordt niet afgedaan door het feit dat een persoon naar nationaal recht op fiscale, administratieve of bureaucratische gronden als zelfstandige is aangeworven, voor zover die persoon onder leiding van zijn werkgever handelt wat betreft onder meer de vrijheid om zijn tijdschema en de plaats en de inhoud van zijn werk te kiezen, hij niet deelt in de commerciële risico's van die werkgever en hij tijdens de duur van de arbeidsverhouding is opgenomen in de onderneming van die werkgever, waarmee hij een economische eenheid vormt. ${ }^{23} \mathrm{De}$ nationale rechter moet verifiëren of de remplaçanten zich, ook al zijn zij werkzaam op basis van een overeenkomst van opdracht, niet in een ondergeschiktheidsrelatie met het betrokken orkest bevinden tijdens de duur van de contractuele verhouding en dus vergeleken met werknemers die hetzelfde werk verrichten over meer zelfstandigheid en flexibiliteit beschikken voor wat betreft de bepaling van het tijdschema, de plaats en de wijze van uitvoering van de toevertrouwde taken, te weten de repetities en concerten. ${ }^{24}$

Als er inderdaad geen sprake is van ondernemingen maar van schijnzelfstandigen dan kan de immuniteit voor mededingingsrecht wel ingeroepen worden als het doel van de bepalingen dat rechtvaardigt. Het Hof van Justitie merkte op dat het stelsel van minimumtarieven van de cao rechtstreeks bijdraagt tot verbetering van de werkgelegenheids- en arbeidsvoorwaarden van die - als schijnzelfstandigen aangemerkte - remplaçanten. ${ }^{25}$

\section{De betekenis van het arrest FNV Kiem}

Opvallend zijn de verschillen tussen de benadering van het Hof van Justitie en de advocaat-generaal met betrekking tot schijnzelfstandigen. Ook de advocaat-generaal onderkende dat er schijnzelfstandigen kunnen zijn. Hij vindt echter dat de cao betrekking heeft op echte zelfstandigen. Met andere woorden, ook al ziet hij in dat zij in vergelijkbare omstandigheden kunnen verkeren als werknemers, hij vindt het geen houdbare oplossing om voor de in de cao bedoelde zelfstandigen een uitzondering te maken op de mededingingsregels. Anders is er sprake van onzekerheid en onvoorzienbaarheid (punt 62).

Het Hof van Justitie koos, zoals we zagen, voor een andere benadering, door kritisch te zijn ten aanzien van de vraag of er wel sprake is van zelfstandigen. Het Hof van Justitie gaf in zijn overwegingen geen scherpe definitie van werknemer, maar overwoog dat men ook werknemer kan zijn als men als zelfstandige is aangeworven, voor zover men onder leiding van de werkgever handelt wat betreft onder meer de vrijheid om zijn tijdschema

23. FNV Kiem, punt 36

24. FNV Kiem, punt 37
25. FNV Kiem, punt 39 
en de plaats en de inhoud van het werk te kiezen, men niet deelt in de economische risico's van die werkgever en is opgenomen voor de duur van de arbeidsverhouding in de onderneming van die werkgever. ${ }^{26}$ De eis van de gezagsverhouding en persoonlijk arbeid moeten verrichten lijkt hiermee te zijn uitgewerkt in de eis dat men in de organisatie van de werkgever past voor wat betreft de bepaling van het tijdschema, de plaats en de wijze van uitvoering van de toevertrouwde taken, waardoor men eenvoudiger zal voldoen aan de voorwaarden voor werknemerschap.

De door het Hof van Justitie gehanteerde criteria zijn ruimer dan volgens het nationale arbeidsrecht, aangezien de remplaçanten ook als ze een overeenkomst tot opdracht hebben, zich kunnen laten vervangen en er twijfels zijn of er een gezagsrelatie in het algemeen is met de werkgever, toch tijdens hun contractuele verhouding als werknemer kunnen worden beschouwd, namelijk als ze over niet meer vrijheid beschikken dan de werknemers bij het tijdschema, de plaats en de uitvoering van taken.

Dit maakt wel verschil. Zo werden de concertremplaçanten met overeenkomst tot opdracht als zelfstandigen beschouwd in de cao en door het Hof 's-Gravenhage en advocaat-generaal Wahl als ondernemers, terwijl de benadering van het Hof van Justitie waarschijnlijk tot de conclusie leidt dat er sprake is van schijnzelfstandigen. Concertremplaçanten moeten zich immers aan voorschriften van plaats, tijd en inhoud houden, want anders kan een orkest niet functioneren. Dat zij zich eventueel mogen laten vervangen is dus niet relevant.

Volgens het dictum van het arrest moet het Hof 's-Gravenhage onderzoeken of de dienstverleners zich in een situatie bevinden die vergelijkbaar is met die van werknemers, dus in het dictum worden de zojuist genoemde criteria weer niet vermeld. Het ligt echter voor de hand dat die vergelijking in het licht van de genoemde criteria moet geschieden en dat zou bij de concertremplaçanten mijns inziens tot geen andere conclusie kunnen leiden dat dat er sprake is van schijnzelfstandigen.

Overigens blijven zij zelfstandigen naar Nederlands recht, zodat zij voor werkgevers goedkoper kunnen blijven dan werknemers, omdat bijvoorbeeld het ontslagrecht niet geldt of bepalingen omtrent doorbetalen van loon als er geen werk is of bij ziekte. De benadering van het Hof van Justitie heeft enkel belang voor het EUrecht, in casu het mededingingsrecht. Daarmee is goed denkbaar dat ook werkgeversorganisaties kunnen leven met minimumtarieven voor schijnzelfstandigen en daarom akkoord gaan met dergelijke cao's.

\section{Tot slot}

FNV Kiem was in eerste instantie teleurgesteld dat het niet geoorloofd is minimumbepalingen te maken die betrekking hebben op (echte) zelfstandigen. Dat het

26. FNV Kiem, punt 36 geoorloofd is om bepalingen overeen te komen die betrekking hebben op schijnzelfstandigen lijkt op het eerste gezicht inderdaad een dode mus: schijnzelfstandigen zijn immers werknemers en cao's hebben zonder twijfel betrekking op hen. Het begrip schijnzelfstandige zoals door het Hof van Justitie geformuleerd kan er echter toe leiden dat er meer mogelijkheden zijn om regelingen te treffen voor bepaalde categorieën zelfstandigen dan onder het Nederlandse recht. Probleem is wel dat de definitie van het Hof van Justitie niet heel scherp is:

'voor zover die persoon onder leiding van zijn werkgever handelt wat betreft onder meer de vrijheid om zijn tijdschema en de plaats en de inhoud van zijn werk te kiezen, hij niet deelt in de commerciële risico's van die werkgever en hij tijdens de duur van de arbeidsverhouding is opgenomen in de onderneming van die werkgever'.

Daar kunnen in de praktijk nog wel eens interpretatievragen over rijzen. Wanneer is bijvoorbeeld sprake van zoveel vrijheid dat niet aangenomen wordt dat er sprake is van werknemerschap?

Het begrip schijnzelfstandige volgens het Hof van Justitie beperkt zich bovendien tot dienstverleners die in de organisatie van een werkgever opgenomen zijn. Bij concertremplaçanten is dat het geval, bij vertalers en andere (creatieve) beroepen meestal niet, en dat betekent dat (te) lage tarieven bij hen niet met een cao aangepakt kunnen worden. Dat neemt niet weg dat dit arrest aangegrepen kan worden om waar mogelijk en zinnig regelingen te treffen (minimumtarieven, wellicht ook opname in pensioenregelingen) die ook van toepassing zijn op de zzp'ers die voldoen aan de criteria van schijnzelfstandigen. Dat zijn er genoeg. ${ }^{27}$ Denk bijvoorbeeld aan de vele zzp'ers in de bouw die op door de opdrachtgever bepaalde plaatsen en tijdstippen moeten werken, omdat samenwerking met anderen hier essentieel is. Ook zzp'ers werkzaam in het busvervoer vallen in deze categorie. Inmiddels heeft de Rechtbank Zeeland-West-Brabant bepaald dat het $F N V$ Kiem-arrest ook van belang is voor de uitleg van artikel 53 van de Cao voor het Besloten Busvervoer: de rechter verklaart voor recht dat dit artikel slechts rechtsgeldig is voor zzp'ers die schijnzelfstandigen zijn in de zin van FNV Kiem. ${ }^{28}$ Naar alle waarschijnlijkheid heeft het arrest ook consequenties voor werknemers in de thuiszorg. Ook hier is een strakke organisatie nodig; cliënten wachten immers op de thuiszorgmedewerker. Daarmee is het mogelijk om door middel van cao's hun positie te verbeteren.

Aangezien het arrest de benadering van Albany bevestigt, heeft het voor het leerstuk van mededinging niet veel nieuws opgeleverd. Dat kan anders zijn voor (nationale) sociale politiek, als cao-partijen het erover eens worden om bepalingen in de cao op te nemen die de positie van schijnzelfstandigen verbeteren.

27. Zie ook de noot bij FNV Kiem in JAR 2015/19 door A. Stege.

28. Rb. Zeeland-West Brabant 11 februari 2015, ECLI:NL:RBZWB: 2015:813. 